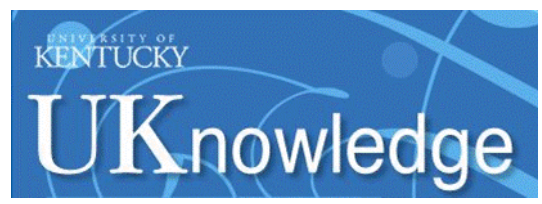

University of Kentucky

UKnowledge

$12-18-2016$

\title{
Alcohol Use and Strenuous Physical Activity in College Students: A Longitudinal Test of 2 Explanatory Models of Health Behavior
}

\author{
Heather A. Davis \\ University of Kentucky, h.davis@uky.edu \\ Elizabeth N. Riley \\ University of Kentucky, elizabeth.n.riley@uky.edu \\ Gregory T. Smith \\ University of Kentucky, gsmith@uky.edu \\ Richard S. Milich \\ University of Kentucky, richard.milich@uky.edu \\ Jessica L. Burris \\ University of Kentucky, burris.jessica@gmail.com
}

Follow this and additional works at: https://uknowledge.uky.edu/psychology_facpub

Part of the Behavior and Behavior Mechanisms Commons, Higher Education Commons, Psychology Commons, Public Health Commons, and the Substance Abuse and Addiction Commons

Right click to open a feedback form in a new tab to let us know how this document benefits you.

\section{Repository Citation}

Davis, Heather A.; Riley, Elizabeth N.; Smith, Gregory T.; Milich, Richard S.; and Burris, Jessica L., "Alcohol Use and Strenuous Physical Activity in College Students: A Longitudinal Test of 2 Explanatory Models of Health Behavior" (2016). Psychology Faculty Publications. 189.

https://uknowledge.uky.edu/psychology_facpub/189

This Article is brought to you for free and open access by the Psychology at UKnowledge. It has been accepted for inclusion in Psychology Faculty Publications by an authorized administrator of UKnowledge. For more information, please contact UKnowledge@lsv.uky.edu. 


\section{Alcohol Use and Strenuous Physical Activity in College Students: A Longitudinal Test of 2 Explanatory Models of Health Behavior}

Digital Object Identifier (DOI)

https://doi.org/10.1080/07448481.2016.1260571

Notes/Citation Information

Published in Journal of American College Health, v. 65, issue 2, p. 112-121.

(C) 2017 Taylor \& Francis

The copyright holder has granted the permission for posting the article here.

This is an Accepted Manuscript of an article published by Taylor \& Francis in Journal of American College Health on 18 Dec 2016, available online: http://www.tandfonline.com/10.1080/07448481.2016.1260571. 
J Am Coll Health. 2017 ; 65(2): 112-121. doi:10.1080/07448481.2016.1260571.

\title{
Alcohol use and strenuous physical activity in college students: A longitudinal test of 2 explanatory models of health behavior
}

\author{
Heather A. Davis, MS ${ }^{a}$, Elizabeth N. Riley, MS ${ }^{a}$, Gregory T. Smith, PhD ${ }^{a}$, Richard Milich, \\ PhD $^{a}$, and Jessica L. Burris, PhD ${ }^{a, b}$ \\ aDepartment of Psychology, University of Kentucky, Lexington, Kentucky, USA \\ bMarkey Cancer Center, University of Kentucky, Lexington, Kentucky, USA
}

\begin{abstract}
Objective-To help clarify the effect of gender on the bidirectional relationship between alcohol use and strenuous physical activity in college students.

Participants-Five hundred twenty-four (52\% female) college students recruited in August 2008 and 2009 and followed up in April 2009 and April 2011, respectively.

Methods-Participants reported their alcohol use and strenuous physical activity on 2 occasions (baseline and follow-up) spaced approximately 1 or 2 years apart.

Results-For females, alcohol use quantity at baseline was associated with increased strenuous physical activity at 1- and 2-year follow-ups, and alcohol use frequency at baseline was associated with decreased strenuous physical activity at 2-year follow-up. For males, alcohol use frequency at baseline predicted decreased strenuous physical activity at 1-year follow-up.

Conclusions-Gender differences may be explained from an eating disorders perspective such that women use physical activity as a compensatory strategy to combat potential weight gain from calories consumed during alcohol use.
\end{abstract}

\section{Keywords}

Alcohol; college; students; drinking; gender; physical; activity

Physical activity (PA) is well known to protect against chronic disease and improve quality of life. ${ }^{1,2}$ Consequently, the US Department of Health and Human Services recommends adults engage in at least 150 minutes of moderate, or 75 minutes of vigorous/strenuous, PA each week. ${ }^{2}$ Population-based estimates of PA indicate only half of US adults met these guidelines in $2012,{ }^{3}$ far below the Healthy People 2020 benchmarks. ${ }^{2}$ PA levels differ across groups, however, with younger adults being more active than older adults. ${ }^{4}$

CONTACT: Heather A. Davis, h.davis@uky.edu, 111-H Kastle Hall, Lexington, KY 40506-0044.

Conflict of interest disclosure

The authors have no conflicts of interest to report. The authors confirm that the research presented in this article met the ethical guidelines, including adherence to the legal requirements, of the United States and received approval from the Institutional Review Board of the University of Kentucky. 
In contrast to PA, alcohol poses a risk to public health, particularly when consumed frequently or in large amounts by young adults. ${ }^{5}$ Alcohol use (AU) increases risk for violent crimes and injuries, ${ }^{6}$ and in some cases, it increases risk for health problems. ${ }^{7}$ The full nature of risks associated with $\mathrm{AU}$ is not the same across all groups. Among young adults in college, for example, $\mathrm{AU}$ is normative,${ }^{8}$ despite over half being under the legal drinking age. ${ }^{8}$ Thus, for these young adults, $\mathrm{AU}$ carries the threat of legal problems in addition to risk for other problematic behaviors (eg, unprotected sex ${ }^{9}$ ).

Health-promoting behaviors tend to co-occur, and empirical research shows that PA generally co-occurs alongside other health protective behaviors (eg, fruit/vegetable consumption, seatbelt use ${ }^{10,11}$ ). Nonetheless, PA's protective effects may not extend to AU. ${ }^{12}$ In college students, some studies and that PA is positively associated with $\mathrm{AU},{ }^{13-16}$ whereas other studies show that PA is inversely associated with binge drinking ${ }^{17,18}$ and a substance use disorder diagnosis. ${ }^{19}$ Inconsistency among findings creates confusion about the true nature of the relationship between PA and AU, particularly in young adult and college samples.

Most studies do not explore whether and how PA functions differently for females versus males. Exceptions include 2 recent studies with US college students. First, Buscemi and colleagues ${ }^{20}$ found a positive relationship between strenuous and moderate PA (treated separately) and AU quantity in males, but not females. Second, Barry and colleagues ${ }^{21}$ found a positive relationship between PA and AU in males, and a negative relationship in females. Although these studies help clarify a PA-AU link, the findings are again inconsistent, and because both studies are cross-sectional, they do not allow inferences about causal effects. Thus, it remains unclear whether greater PA leads to greater/lesser AU, or greater AU leads to greater/lesser PA, or if the relationship is indeed bidirectional. Further, if longitudinal processes are present, it is still unclear as to if and/or how they operate differently for males and females.

An additional consideration is the reason or motive for PA. Frequent or prolonged strenuous PA (ie, "excessive exercise") for the purpose of altering or maintaining weight or shape is a risk factor for eating disorders. ${ }^{22}$ Excessive exercise is common within the eating disorders of anorexia nervosa and bulimia nervosa, ${ }^{22-24}$ and it is associated with harm and distress even in the absence of a formal eating disorder diagnosis and other disordered eating behaviors. ${ }^{22,25-28}$ Importantly, PA within eating disorders is often used as a compensatory strategy for the consumption of calories, ${ }^{27}$ whether the consumption was objectively ${ }^{29}$ or subjectively ${ }^{30}$ large. From this standpoint, college students may engage in high levels of PA to compensate for calories consumed when drinking alcohol. Therefore, gender differences in the relationship between PA and AU may be particularly relevant due to the emphasis of the thin ideal in females versus males. ${ }^{31}$

\section{Current study}

This longitudinal study explores gender differences in the bidirectional relationship between PA and AU among college students. We used 2 samples, and assessment of study variables occurred on 2 occasions (ie, baseline and follow-up) spaced approximately 1 or 2 years apart 
(Cohorts 1 and 2, respectively). This longitudinal design allowed our exploratory examination of the bidirectional relationships between PA and AU, and for the ability to control for one behavior when predicting the other. The use of 2 cohorts allowed us to assess whether any longitudinal relationships evident in the short term (ie, Cohort 1, 1-year followup) would also hold in the long term (ie, Cohort 2, with 2-year follow-up).

Two explanatory models for the longitudinal relationship between PA and AU are explored. The first research question concerns how AU impacts future engagement in PA. Based on the eating disorder literature, and consistent with PA as a compensatory strategy, we hypothesized that more AU at baseline would be associated with increased PA at follow-up, and that this relationship will be stronger for females than males. The second research question concerns how engagement in PA impacts future AU. Based on literature that shows the clustering of health-promoting behaviors, we predicted that more PA at baseline would be associated with less alcohol consumption at follow-up.

\section{Methods}

\section{Participants}

This study is part of a larger project in which 526 college students answered questions about their personality, substance use, and other health behaviors. The sample size for all analyses herein is 524 (51.91\% female), however, because 2 participants were excluded due to missing data on gender. As mentioned above, data were collected in 2 cohorts $(n=228$ and $n$ $=296$, respectively). The mean age of participants at baseline (an assessment that occurred in their freshman year) was 18.95 years, and most were under 21 years of age (98.07\%). In Cohort 1, most participants identified as Caucasian (86.08\%), African American (9.13\%), or other (4.78\%). In Cohort 2, the majority of participants identified as Caucasian (77.36\%), African American (14.86\%), or other (7.77\%). The gender, age, and racial composition of the sample at baseline closely reflects that of the larger student body from which participants were recruited (data not shown), with the caveat that participants are younger due to their freshman status. In terms of their demographics, Cohorts 1 and 2 only significantly differed on race ( $p=.02$ ), a difference not deemed clinically meaningful because neither measures of PA nor AU differed across racial groups in this study. Furthermore, since race was not associated with our variables of interest $(p>.05)$, we did not include it in our models.

\section{Measures}

Alcohol use-The Alcohol Use Disorder Identification Test (AUDIT) ${ }^{32}$ consists of 10 questions that tap frequency, quantity, and psychosocial consequences of $\mathrm{AU}$ (eg, harm to self or others). Internal consistency in the current sample was high $(a=.81)$. This question assesses frequency: "How often do you have a drink containing alcohol?" Response options include: $0=$ Never, $1=$ Monthly or less, $2=2-4$ times per month, $3=2-3$ times per week, and $4=4+$ times per week. The question "How many units of alcohol do you drink on a typical day when you are drinking?" assesses quantity. Response options include $0=1-2,1$ $=3-4,2=5-6,3=7-9$, and $4=10+$. AU frequency and quantity were considered separately. 
Physical activity-Consistent with PA assessment in population-based surveys ${ }^{3}$ and other recent studies, ${ }^{33}$ participants' PA was measured with a modified Leisure Time Exercise Questionnaire. ${ }^{34}$ The measure included 3 questions that assess the frequency and average duration (minutes) of strenuous, moderate, and mild PA in the past week. Participants were instructed to only consider PA performed during their free time (ie, not in the context of household chores or work). To aid accurate self-reports, verbal descriptors and examples were provided for each intensity level (eg, strenuous—-heart beats rapidly, sweating; examples: running, swimming). Research on the reliability and validity of self-report PA measures supports use of the Leisure Time Exercise Questionnaire and similar approaches. ${ }^{35}$ Strenuous PA (and total PA) was calculated by multiplying participants' frequency and duration of exercise over the past week.

\section{Procedure}

Participants were recruited from introductory psychology courses at a large, public university in the southeastern United States; of note, such courses are not limited to psychology majors or minors. Informed consent was obtained from participants prior to each assessment. Each assessment involved individual, in-person, structured interviews with a research assistant and completion of questionnaires on a computer in a private laboratory setting. Participants received course credit and $\$ 30$ for completion of the baseline. They received $\$ 50$ for completion of the follow-up. This study was approved by the university's institutional review board (IRB), and a federal Certificate of Confidentiality was obtained.

\section{Data analysis}

Data were collected for 524 participants at baseline. The retention rate at follow-up for Cohorts 1 (1-year follow-up) and 2 (2-year follow-up) was $86.25 \%(n=452)$ and $79.58 \%(n$ $=417$ ), respectively. Analyses comparing retained and nonretained participants on demographic (gender, age, race) and other study variables (PA and AU) indicated no significant differences (all $p s>.05$ ). We therefore assumed data were missing at random and used the expectation maximization procedure to impute values for any missing data. This procedure is known to produce relatively unbiased population parameter estimates and is superior to traditional methods. ${ }^{36}$

Descriptive statistics and bivariate correlations were used in advance of hypothesis tests. To test our conceptual models, we used structural equation modeling (SEM). The variables included in SEM were gender, AU frequency, AU quantity, and strenuous PA. We proceeded through a series of model tests. In each model, we allowed cross-sectional associations between all variables or disturbance terms. We conducted these tests separately by cohort due to time-lag differences between baseline and follow-up.

The first SEM (Model 1) specified autoregressive predictions within all key variables (ie, AU frequency, AU quantity, and strenuous PA). Thus, the "baseline" model involved AU at baseline predicting AU at follow-up and PA at baseline predicting PA at follow-up. In Model 2, prospective prediction pathways between AU frequency and AU quantity at each time point were added. Because AU frequency and quantity are typically highly related, ${ }^{37}$ it was important to model these predictive effects. Fit indices were then examined to test whether 
this model fit the data significantly better than did the first model. ${ }^{38}$ In Model 3, we included prediction from PA at baseline to AU at follow-up. By testing whether this model fit the data better than did the second model, we examined if it is appropriate to treat PA as a predictor of subsequent AU. In Model 4, we added predictive pathways from AU frequency/quantity (measured separately) to PA at follow-up in order to test fully the hypothesized bidirectional pathways. Finally, Model 5 included tests of the invariance of the predictive pathways by gender. We first tested whether the same structural model fit for both genders, and in the next step we added the additional constraint that the pathways from AU to subsequent PA were the same for both genders. As the key research question is whether those paths differ for males and females, we tested whether imposing this constraint would result in significantly reduced model it.

We measured model fit using 4 common indices: comparative fit index (CFI), Tucker-Lewis index (TLI), root mean square error of approximation (RMSEA), and standardized root mean square residual (SRMR). Guidelines for these indices vary: CFI and TLI values of .90 or .95 represent good fit ${ }^{39}$; RMSEA values of .06 indicate a close fit, .08 a fair fit, and .10 a marginal fit ${ }^{39,40}$; and SRMR values of .09 indicate good fit. ${ }^{39}$ Overall model fit is evaluated by considering the values of all fit indices. To compare models, we (a) conducted a chi-square $\left(\chi^{2}\right)$ difference test, which determines whether the more constrained model its the data significantly worse than the less constrained model; and (b) compared fit index values to judge if the drop in fit with more constraints was meaningful. We used Mplus $6.2^{38}$ to run the analyses.

\section{Results}

\section{Descriptive information for PA and AU variables}

Tables 1 and 2 provide descriptive information for PA and AU, respectively. There was considerable variability in the degree of strenuous PA, with some individuals reporting very extensive engagement in the behavior. Thus, strenuous PA was not normally distributed (Cohort 1: baseline skewness $=9.54$, kurtosis $=108.67$; follow-up skewness $=6.16$, kurtosis $=42.18$; Cohort 2: baseline skewness $=2.86$, kurtosis $=10.73$; follow-up skewness $=2.09$, kurtosis $=4.68$ ). In advance of any further data analysis, we next conducted an inverse transformation on the variable in order to achieve normality ${ }^{41}$ (Cohort 1: baseline skewness $=0.44$, kurtosis $=-1.54$; follow-up skewness $=0.90$, kurtosis $=-0.48$; Cohort 2: baseline skewness $=0.78$, kurtosis $=-1.28$; follow-up skewness $=0.54$, kurtosis $=-1.38$ ).

\section{Correlations between PA and AU variables, by gender}

Tables 3 and 4 show correlations among the key study variables, separately for Cohorts 1 and 2, respectively. As shown, AU quantity and frequency were consistently, positively correlated with one another. For Cohort 1, AU quantity at baseline was positively associated with strenuous PA at follow-up for females. Also for Cohort 1, strenuous PA was negatively correlated with AU frequency and quantity at baseline and follow-up for males. For Cohort 2, AU frequency at baseline was negatively associated with strenuous PA at follow-up for females. 


\section{Hypothesis tests: SEMs}

Cohort 1-Model 1 tested the autoregressive pathways across the 1-year observation period. This model did not fit the data well: $\chi^{2}(6)=49.22, p<.001$; CFI $=.90$; TLI $=.81$; RMSEA $=.18 ;$ SRMR $=.07$. Each autoregressive pathway was significant: baseline strenuous PA predicted follow-up strenuous PA $(b=.28, p<.001)$, baseline AU frequency predicted follow-up AU frequency $(b=.79, p<.001)$, and baseline AU quantity predicted follow-up AU quantity $(b=.79, p<.001)$.

Model 2, which involved AU frequency predicting quantity (and vice versa), fit the data better: $\chi^{2}(4)=6.15, p=.18, \chi^{2}$ change from Model $1=\chi^{2}(2)=43.07, p<.001 ;$ CFI $=.99$; $\mathrm{TLI}=.98 ; \mathrm{RMSEA}=.05 ; \mathrm{SRMR}=.03$. The 2 new predictive pathways were significant at $p$ $<.001$.

The new pathways in Model 3 (from strenuous PA at baseline to AU frequency and quantity at follow-up) did not improve model fit: $\chi^{2}(2)=4.04, p=.13$; CFI D .99; TLI = .97; RMSEA $=.07$; SRMR $=.03$. Accordingly, Model 2 is preferred over Model 3, because it fits the data equally well and is more parsimonious.

Model 4 thus incorporated Model 2 with the addition of key predictive pathways from baseline AU frequency and quantity to strenuous PA at follow-up. This model fit the data well: $\chi^{2}(2)=2.07, p=.36$; CFI $=1.0$; TLI $=1.0$; RMSEA $=.01$; SRMR $=.01$. In this model, AU frequency predicted lower levels of subsequent strenuous PA $(b=.16, p<.05)$, but AU quantity was not a significant predictor of subsequent strenuous PA $(b=.08, p=$. $33)$.

Model 5 involved invariance testing by gender on Model 4. We first specified the same structural model for both genders, which resulted in good model fit: $\chi^{2}(4)=6.16, p=.19$; $\mathrm{CFI}=.99 ; \mathrm{TLI}=.97 ; \mathrm{RMSEA}=.07(90 \%$ confidence interval $[\mathrm{CI}]=.00-.17) ; \mathrm{SRMR}=.02$. Next, we constrained 2 pathways to be equal across gender: baseline AU quantity to followup strenuous PA and baseline AU frequency to follow-up strenuous PA. These constraints resulted in a significant drop in model fit: overall $\chi^{2}(6)=16.96, p<.01 ; \chi^{2}$ change from Model $2=\chi^{2}(4)=10.76, p<.05 ; \mathrm{CFI}=.98$; TLI $=.90$; RMSEA $=.13(90 \% \mathrm{CI}=.06-.20)$; $\mathrm{SRMR}=.07$. Thus, the constraint was not justified. As Figure 1 shows, when the paths are not constrained to be equal across gender, AU frequency was negatively related to subsequent PA (this path was significant for males only, $b=-.33, p<.05$; for females $b=-$. $13, p=.14)$. AU quantity, although unrelated to subsequent PA for males $(b=.03, p=.78)$, predicted greater levels of subsequent strenuous PA for females $(b=.25, p<.01)$.

Cohort 2-We conducted the same series of model tests on Cohort 2, which involved a 2year observation period. We briefly summarize the results below.

Model 1 did not fit the data well: $\chi^{2}(6)=32.04, p<.001 ; \mathrm{CFI}=.91$; TLI $=.82$; RMSEA $=$. 12; SRMR $=.06$. Model 2 fit the data better: $\chi^{2}(4)=10.81, p<.05 ; \chi^{2}$ change from Model $1: \chi^{2}(2)=21.23, p<.001$; CFI $=.98$; TLI $=.93$; RMSEA $=.08$; SRMR $=.04$. Model $3 \mathrm{did}$ not improve model fit: $\chi^{2}(2)=10.15, p<.01 ; \chi^{2}$ change from Model 2: $\chi^{2}(2)=0.66, p n s$; $\mathrm{CFI}=.97$; TLI $=.83$; RMSEA $=.12$; SRMR $=.04$. As was true for Cohort 1 , Model 2 is 
preferred over Model 3. Model $4 \mathrm{ft}$ the data well: $\chi^{2}(2)=0.12, p=.94$; CFI $=1.0$; TLI $=$ $1.0 ;$ RMSEA $=.00 ;$ SRMR $=.00$. As was true of this model in Cohort 1, AU frequency predicted lower levels of subsequent strenuous PA, $b=.22, p<.01$.

Model 5 again involved invariance testing by gender on Model 4. We first specified the same structural model for both genders, and doing so resulted in good model fit: $\chi^{2}(4)=3.84, p$ $=.43 ; \mathrm{CFI}=1.0 ; \mathrm{TLI}=1.0 ; \mathrm{RMSEA}=.00(90 \% \mathrm{CI}=.00-.02)$; SRMR $=.02$. Constraints across gender resulted in a significant drop in model fit: overall $\chi^{2}(6)=13.92, p<.01 ; \chi^{2}$ change from Model $4=\chi^{2}(2)=10.08, p<.05 ;$ CFI $=.97$; TLI $=.90 ;$ RMSEA $=.09(90 \%$ $\mathrm{CI}=.03-.16) ; \mathrm{SRMR}=.03$. Thus, the constraint was not justified. As Figure 2 shows, AU frequency negatively predicted subsequent strenuous PA for females only $(b=-14, p<$. $001)$. AU quantity predicted greater levels of subsequent strenuous PA for females $(b=.12$, $p<.001)$.

\section{Comment}

The current study, we believe, is the first to longitudinally examine gender differences in the relationship between engagement in strenuous PA and AU during the college years. We found that AU quantity predicted an increase in strenuous PA 1 and 2 years later for female, but not male, students. AU frequency, on the other hand, predicted a decrease in strenuous PA 1 year later for male students and 2 years later for female students. Thus, the 2 facets of AU studied herein were observed to be robust and unique predictors of PA at a later date. The findings for AU quantity are consistent with a compensatory strategy as seen in eating disorder research and may be indicative of a habit of engaging in "damage control" to compensate for the unhealthy behavior of consuming a large amount of alcohol. The findings for AU frequency are consistent with the large body of cross-sectional research that shows that some health protective behaviors cluster together (ie, less AU and more PA are a part of a broad approach to healthy living ${ }^{10,11}$ ). It is plausible that college students who engage in frequent AU simply may not feel well enough to engage in strenuous PA and eventually give up on a healthy lifestyle due to all-or-nothing thinking about health behaviors. Given the divergent effects observed for AU frequency and quantity, it is imperative that future studies in this area separate these variables so as to avoid inconsistent or null findings when examining PA as an outcome. Finally, and in contrast to the above, strenuous PA did not evidence a predictive effect on AU for male or female students.

This study's major finding is that for females (but not males), the quantity of AU in their freshman year of college was associated with increased strenuous PA in their sophomore and junior years of college. Gender differences in these results may be explained by gender differences in expectations for body shape and weight. These results could reflect a tendency for females to combat any potential weight gain secondary to AU by engaging in strenuous PA. Consistent with an extensive body of evidence from the eating disorders literature, ${ }^{22}$ the desire to combat calories and maintain shape and weight via strenuous PA may well extend to the calories consumed when drinking. Because men do not appear to have the same desire for a thin physique, ${ }^{42}$ they may not experience the same drive to exercise strenuously in response to heavy calorie intake. In support of this line of thinking, Bryant et $\mathrm{al}^{43}$ found that although some college students endorse weight control behaviors (eg, strenuous PA) in 
anticipation of calories consumed during $\mathrm{AU}$, more students endorse strenuous PA to make up for the calories already consumed. This same study found that twice as many women endorsed PA as a means of compensating for calories consumed via AU than men. A compensatory model of PA seems plausible if one considers acute episodes of AU and PA (eg, binge drinking on Friday night and exercising on Saturday morning), but what is particularly remarkable about the findings herein is the evidence of a long-term relationship.

In eating disorder studies with college females, one third to one half report using excessive exercise to combat caloric consumption or maintain weight and shape. ${ }^{26,44}$ Among females in this sample, $63 \%$ reported strenuous PA at baseline and/or follow-up. Further, recommended strenuous activity guidelines are 75 minutes per week of high-intensity cardio or muscle strengthening, ${ }^{2}$ and $37 \%$ of female participants exceeded this guideline at 1 or more time points. Previous studies have found that excessive exercise is associated with eating disorder symptoms and diagnoses. ${ }^{23,24}$ It may be that some females in this study were engaging in other disordered eating behavior, including self-induced vomiting, binge eating, or severe caloric restriction, and thus were suffering from an eating disorder. The opposite may also be true. Because this study did not assess disordered eating behaviors or height and weight, we cannot know how many participants met criteria for an eating disorder. However, excessive exercise in the absence of other eating disorder behaviors is associated with distress. ${ }^{25,28}$ Thus, regardless of the presence or absence of a clinical diagnosis, excessive exercise is a significant problem in itself, warranting attention from both a research and clinical standpoint. The important message is that, for women, strenuous PA may increase significantly in response to increased quantities of AU and may well be a compensatory strategy for caloric consumption.

In contrast to our finding of $\mathrm{AU}$ as a predictor of future PA, the utility of PA to explain future AU was not observed. This differs from other work that supports strenuous PA as a predictor of $\mathrm{AU},{ }^{13,21,45,46}$ particularly in males. ${ }^{20,21}$ As it pertains to females, it is possible our null findings are due to strenuous PA being used as a compensatory rather than a preventative strategy. In other words, strenuous PA largely functions as an outcome and not a predictor. As it pertains to males, however, it is possible the inconsistency between our findings and those of earlier studies is due to methodological differences. Prior work that demonstrates an association between strenuous PA and AU is cross-sectional in design, whereas this study explored the predictive effects of strenuous PA within the context of a longitudinal design, and it did not find such a relationship.

The results and implications of this study should be considered in light of its methodological limitations. First, PA data were self-reported via a questionnaire. Although this is normative for observational studies, ${ }^{33}$ interviews provide opportunities for clarification and objective measures (eg, pedometers) provide greater reliability and validity. Second, as stated above, we did not measure disordered eating cognitions or behavior (other than excessive exercise) nor did we measure PA motives. These measures could have clarified whether participants' self-evaluation was unduly influenced by their shape and weight (a symptom of eating disorders), and whether or not participants use PA with the express purpose of compensating for alcohol-related caloric consumption and/or altering shape and weight. Future studies should therefore seek to clarify the motives behind excessive exercise and strenuous PA 
among college women. Students training for athletic events (eg, team sporting event or marathon) may report levels of strenuous PA akin to those engaging in repeated episodes of excessive exercise in order to compensate for heavy $\mathrm{AU}$, and of course, one behavioral pattern may be considered "healthy" or "adaptive" whereas the other is not. Third, these results may not generalize beyond the current sample. A college student sample was appropriate for this study because young adulthood and college is often a time of heavy AU. ${ }^{47}$ However, we cannot know whether these results would replicate in a sample of young adults not enrolled in college, and particularly so for samples with greater heterogeneity in race and ethnicity. We also cannot be fully confident that these results will hold for students at other colleges and universities, as the culture surrounding attitudes toward AU and PA may vary from campus to campus and across geographic regions. However, it should be noted that the overall AU and PA reported by participants in this study are comparable to those reported by participants in a 2015 survey of college students $(N=16,760)$ from 40 different US schools, ${ }^{48}$ with slightly higher levels of AU in this sample. Finally, we cannot know from these data when participants first began the observed pattern of AU and PA, as it very well may have emerged prior to college.

In conclusion, this study is one of the first to shed light on gender differences in the relationship between PA and AU. It appears that for female college students, the amount and frequency of $\mathrm{AU}$ are important for predicting future strenuous PA, whereas for males, only the frequency of AU demonstrates predictive power. Of note, the quantity and frequency of AU demonstrated very different predictive associations with PA, with one showing a positive effect and the other a negative effect. As a whole, the results of this study should not be used to condemn strenuous PA in female college students. Rather, these findings are meant to increase understanding of the complex longitudinal relationship between AU and strenuous PA in college student and possibly other young adult samples. Based on study findings, future studies should consider the roles of gender and motives when developing theories to explain the arguably counterintuitive relationship between some aspects of AU and PA.

\section{Acknowledgments}

\section{Funding}

Funding for this study was provided by National Institute on Drug Abuse (NIDA) grant DA005312 awarded to the University of Kentucky Center on Drug Abuse Research Translation (CDART) and National Cancer Institute (NCI) grant CA181351 awarded to J. L. Burris.

\section{References}

1. Bauman AE. Updating the evidence that physical activity is good for health: an epidemiological review 2000-2003. J Sci Med Sport. 2004; 7:6-19. [PubMed: 15214597]

2. Healthy People 2020. Washington, DC: US Department of Health and Human Services, Office of Disease Prevention and Health Promotion; http://www.healthypeople.gov/2020/topics-objectives/ topic/physical-activity/objectives. Published November 2010 [Accessed December 2015]

3. National Health Interview Survey (NHIS). Adults engaging in regular physical activity-moderate for $150+$ minutes/week or vigorous for 75+ minutes/week. Centers for Disease Control and Prevention, National Center for Health Statistics; 2013. http://www.healthypeople.gov/2020/data/Chart/5069? category $=1 \&$ by $=$ Total\&fips $=-1$ [Accessed December 2015] 
4. Centers for Disease Control and Prevention. [Accessed December 2015] Facts about physical activity. http://www.cdc.gov/physicalactivity/data/facts.html

5. Chen CM, Dufour MC, Yi HY. Alcohol consumption among young adults ages 18-24 in the United States: results from the 2001-2002 NESARC Survey. Alcohol Res Health. 2004; 28:269-280.

6. Hingson R, Heeren T, Winter M, Wechsler H. Magnitude of alcohol-related mortality and morbidity among US college students ages 18-24: changes from 1998 to 2001. Public Health. 2005; 26:259279.

7. Chen WY, Rosner B, Hankinson SE, Colditz GA, Willett WC. Moderate alcohol consumption during adult life, drinking patterns, and breast cancer risk. JAMA. 2011; 306:1884-1890. [PubMed: 22045766]

8. American College Health Association. American College Health Association-National College Health Assessment II: Undergraduate Students Reference Group Executive Summary Spring 2014. Hanover, MD: American College Health Association; 2014.

9. Scott-Sheldon LA, Carey MP, Carey KB. Alcohol and risky sexual behavior among heavy drinking college students. AIDS Behav. 2010; 14:845-853. [PubMed: 18648928]

10. Boutelle KN, Murray DM, Jeffery RW, Hennrikus DJ, Lando HA. Associations between exercise and health behaviors in a community sample of working adults. Prev Med. 2000; 30:217-224. [PubMed: 10684745]

11. Leech RM, McNaughton SA, Timperio A. The clustering of diet, physical activity and sedentary behavior in children and adolescents: a review. Int J Behavl Nutr Phys Act. 2014; 11:1.doi: 10.1186/1479-5868-11-4

12. Dodd LJ, Al-Nakeeb Y, Nevill A, Forshaw MJ. Lifestyle risk factors of students: a cluster analytical approach. Prev Med. 2010; 51:73-77. [PubMed: 20385163]

13. Barry AE, Piazza-Gardner AK. Drunkorexia: understanding the co-occurrence of alcohol consumption and eating/exercise weight management behaviors. J Am Coll Health. 2012; 60:236243. [PubMed: 22420701]

14. Downs A, Ashton J. Vigorous physical activity, sports participation, and athletic identity: implications for mental and physical health in college students. J Sport Behav. 2011; 34:228-249.

15. Dunn MS, Wang M. Effects of physical activity on substance use among college students. Am J Health Stud. 2003; 18:126-132.

16. Musselman JR, Rutledge PC. The incongruous alcohol-activity association: physical activity and alcohol consumption in college students. Psychol Sport Exerc. 2010; 11:609-618.

17. Correia CJ, Benson TA, Carey KB. Decreased substance use following increases in alternative behaviors: a preliminary investigation. Addict Behav. 2005; 30:19-27. [PubMed: 15561446]

18. Correia CJ, Carey KB, Simons J, Borsari BE. Relationships between binge drinking and substancefree reinforcement in a sample of college students: a preliminary investigation. Addict Behav. 2003; 28:361-368. [PubMed: 12573686]

19. Ströhle A, Höfler M, Pfister H, et al. Physical activity and prevalence and incidence of mental disorders in adolescents and young adults. Psychol Med. 2007; 37:1657-1666. [PubMed: 17579930]

20. Buscemi J, Martens MP, Murphy JG, Yurasek AM, Smith AE. Moderators of the relationship between physical activity and alcohol consumption in college students. J Am Coll Health. 2011; 59:503-509. [PubMed: 21660805]

21. Barry AE, Whiteman S, Piazza-Gardner AK, Jensen AC. Gender differences in the associations among body mass index, weight loss, exercise, and drinking among college students. J Am Coll Health. 2013; 61:407-413. [PubMed: 24010495]

22. Shroff H, Reba L, Thornton LM, et al. Features associated with excessive exercise in women with eating disorders. Int J Eat Disord. 2006; 39:454-461. [PubMed: 16637047]

23. Ackard DM, Brehm BJ, Steffen JJ. Exercise and eating disorders in college-aged women: profiling excessive exercisers. Eat Disord. 2002; 10:31-47. [PubMed: 16864243]

24. Holm-Denoma JM, Scaringi V, Gordon KH, Van Orden KA, Joiner TE. Eating disorder symptoms among undergraduate varsity athletes, club athletes, independent exercisers, and nonexercisers. Int J Eat Disord. 2009; 42:47-53. [PubMed: 18651619] 
25. Davis HA, Holland LA, Keel PK. A preliminary examination of a nonpurging compensatory eating disorder. Int J Eat Disord. 2014; 47:239-243. [PubMed: 24105678]

26. LePage ML, Crowther JH, Harrington EF, Engler P. Psychological correlates of fasting and vigorous exercise as compensatory strategies in undergraduate women. Eat Behav. 2008; 9:423429. [PubMed: 18928905]

27. Mond JM, Hay PJ, Rodgers B, Owen C. An update on the definition of "excessive exercise" in eating disorders research. Int J Eat Disord. 2006; 39:147-153. [PubMed: 16231344]

28. Tobin DL, Griffing A, Griffing S. An examination of subtype criteria for bulimia nervosa. Int J Eat Disord. 1997; 22:179-186. [PubMed: 9261657]

29. American Psychiatric Association. Diagnostic and Statistical Manual of Mental Disorders. 5. Washington, DC: American Psychiatric Association; 2013.

30. Pratt EM, Niego SH, Agras WS. Does the size of a binge matter? Int J Eat Disord. 1998; 24:307312. [PubMed: 9741041]

31. Furnham A, Badmin N, Sneade I. Body image dissatisfaction: gender differences in eating attitudes, self-esteem, and reasons for exercise. J Psychol. 2002; 136:581-596. [PubMed: 12523447]

32. Saunders JB, Aasland OG, Babor TF, De la Fuente JR, Grant M. Development of the alcohol use disorders identification test (AUDIT). WHO Collaborative Project on Early Detection of Persons with Harmful Alcohol Consumption-II. Addiction. 1993; 88:791-804. [PubMed: 8329970]

33. Blanchard C, Fisher J, Sparling P, et al. Understanding physical activity behavior in African American and Caucasian college students: an application of the theory of planned behavior. J Am Coll Health. 2008; 56:341-346. [PubMed: 18316275]

34. Godin G, Shephard RJ. A simple method to assess exercise behavior in the community. Can J App Sport Sci. 1985; 10:141-146.

35. Sallis JF, Saelens BE. Assessment of physical activity by self-report: status, limitations, and future directions. Res Q Exerc Sport. 2000; 71:1-14.

36. Little RJ, Rubin DB. The analysis of social science data with missing values. Sociol Methods Res. 1989; 18:292-326.

37. Gmel G, Heeb JL, Rehm J. Is frequency of drinking an indicator of problem drinking? A psychometric analysis of a modified version of the alcohol use disorders identification test in Switzerland. Drug Alcohol Depend. 2001; 64:151-163. [PubMed: 11543985]

38. Muthen, LK., Muthen, BO. Mplus: The Comprehensive Modeling Program for Applied Researchers. User's Guide. 3. Los Angeles, CA: Muthen \& Muthen; 2004-2010.

39. Hu LT, Bentler PM. Cutoff criteria for fit indexes in covariance structure analysis: conventional criteria versus new alternatives. Struct Equ Modeling. 1999; 6:1-55.

40. Browne, MW., Cudeck, R. Alternative ways of assessing model fit. In: Kenneth, B., Long, JS., editors. Testing Structural Equation Models. Newbury Park, CA: Sage Publications; 1993. p. 136-162.

41. Micceri T. The unicorn, the normal curve, and other improbable creatures. Psychol Bull. 1989; 105:156-166.

42. Stanford JN, Mccabe MP. Body image ideal among males and females: sociocultural influences and focus on different body parts. J Health Psychol. 2002; 7:675-684. [PubMed: 22113409]

43. Bryant JB, Darkes J, Rahal C. College students' compensatory eating and behaviors in response to alcohol consumption. J Am Coll Health. 2012; 60:350-356. [PubMed: 22686357]

44. Schaumberg K, Anderson LM, Reilly E, Anderson DA. Patterns of compensatory behaviors and disordered eating in college students. J Am Coll Health. 2014; 62:526-533. [PubMed: 24911417]

45. Moore MJ, Werch C. Relationship between vigorous exercise frequency and substance use among first-year drinking college students. J Am Coll Health. 2008; 56:686-690. [PubMed: 18477525]

46. VanKim NA, Laska MN, Ehlinger E, Lust K, Story M. Understanding young adult physical activity, alcohol and tobacco use in community colleges and 4-year post-secondary institutions: a cross-sectional analysis of epidemiological surveillance data. BMC Public Health. 2010; 10:208. [PubMed: 20420678] 
47. Knight JR, Wechsler H, Kuo M, Seibring M, Weitzman ER, Schuckit MA. Alcohol abuse and dependence among US college students. J Stud Alcohol. 2002; 63:263-270. [PubMed: 12086126]

48. American College Health Association. American College Health Association-National College Health Assessment II: Undergraduate Students Reference Group Data Report Fall 2015. Hanover, MD: American College Health Association; 2016. 


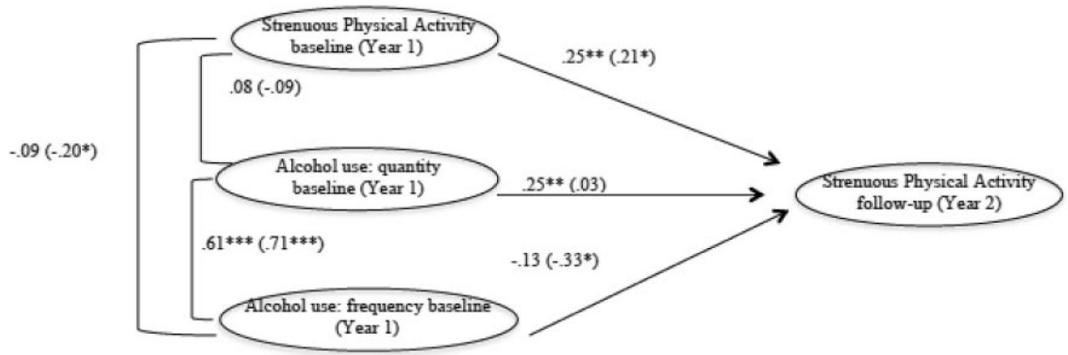

Figure 1.

Final SEM for Cohort 1 (1-year follow-up). Data are for female (male). $\chi^{2}(6)=16.96, p<$ $01 ; \chi^{2}$ change from Model $2=\chi^{2}(4)=10.76, p<.05 ; \mathrm{CFI}=.98 ; \mathrm{TLI}=.90 ; \mathrm{RMSEA}=.13$ $(90 \% \mathrm{CI}=.06-.20)$; SRMR $=.07 .{ }^{*} p \leq 05 ;{ }^{* *} p \leq 01 ;{ }^{* * *} p \leq 001$. 


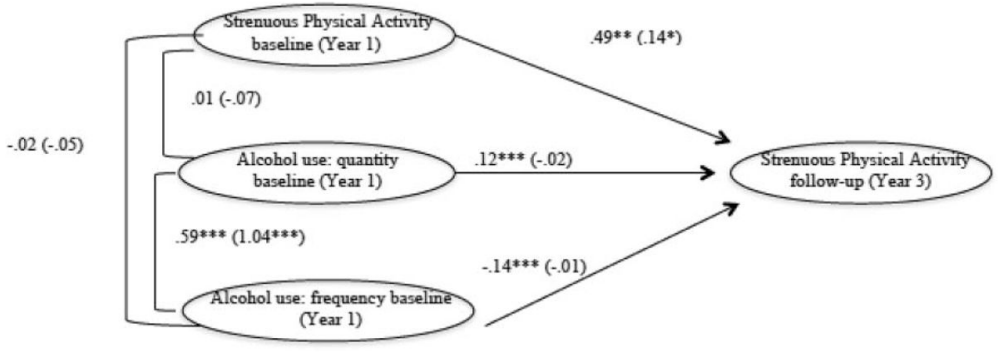

Figure 2.

Final SEM for Cohort 2 (2-year follow-up). Data are for female (male). $\chi^{2}(6)=13.92, p<$. $01 ; \chi^{2}$ change from Model $4=\chi^{2}(2)=10.08, p<.05 ; \mathrm{CFI}=.97 ; \mathrm{TLI}=.90 ; \mathrm{RMSEA}=.09$ $(90 \% \mathrm{CI}=.03-.16) ; \mathrm{SRMR}=.03 .{ }^{*} p \leq 05 ;{ }^{* *} p \leq 01 ;{ }^{* * *} p \leq .001$. 


\section{을 \\ 길}

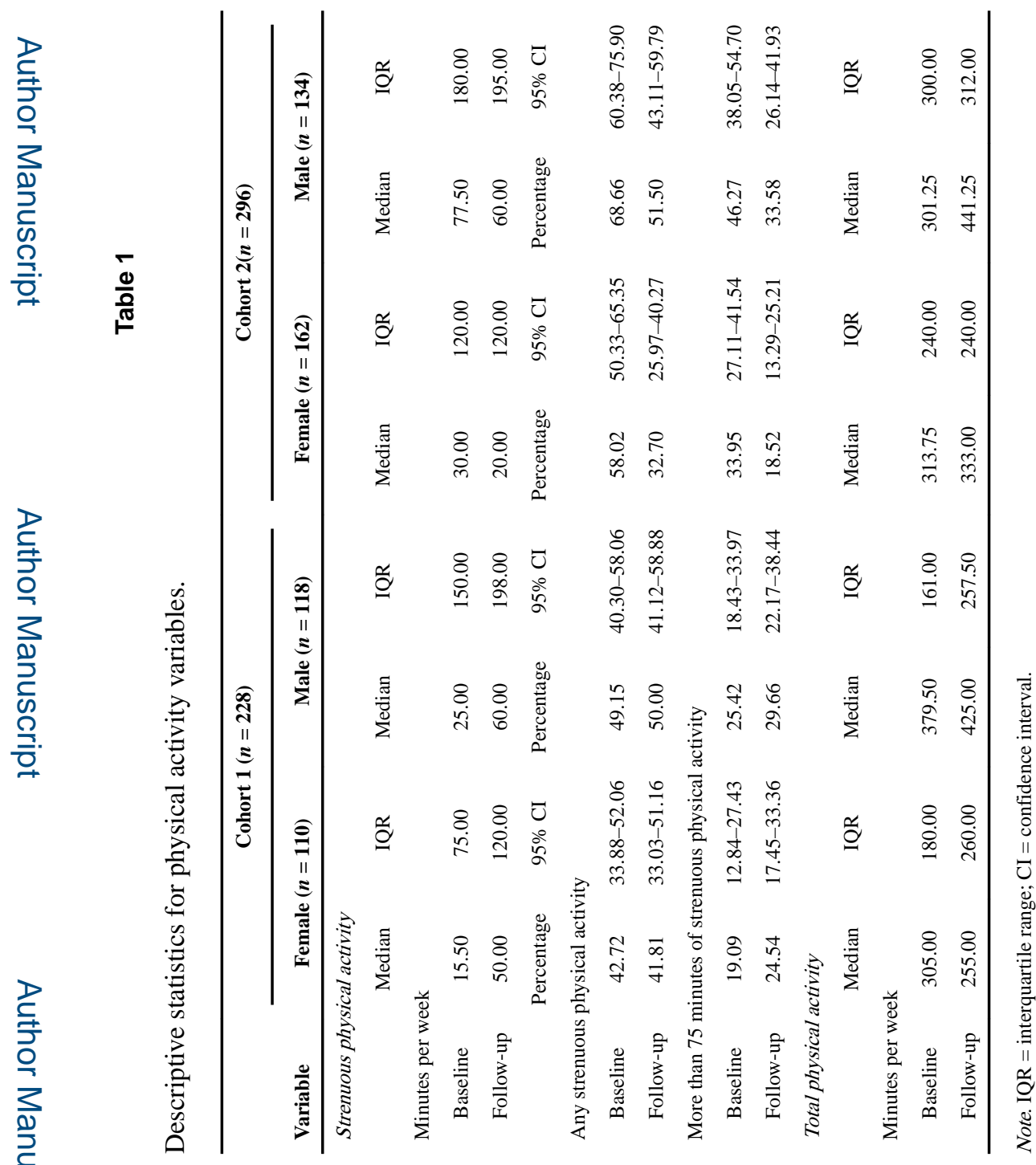

J Am Coll Health. Author manuscript; available in PMC 2018 February 01. 


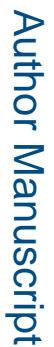

롤

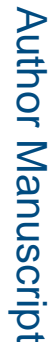

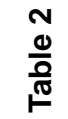

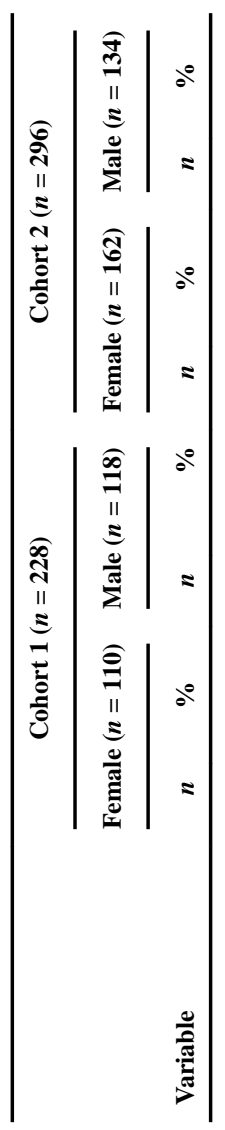

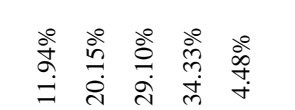

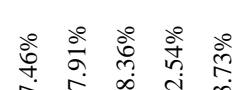

ำ

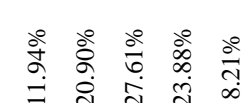

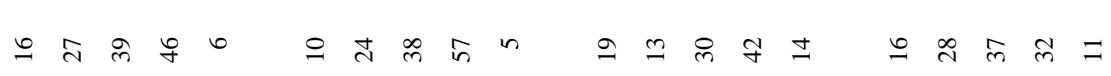

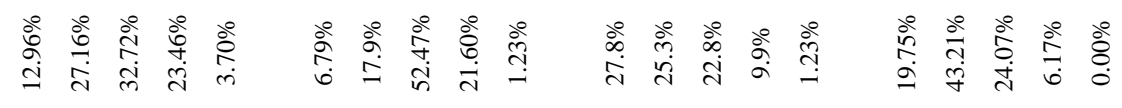

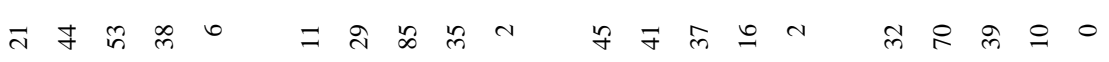

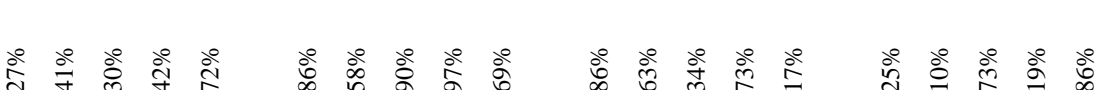
亗过

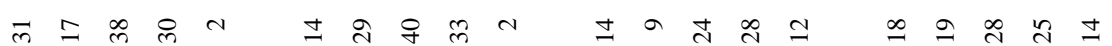

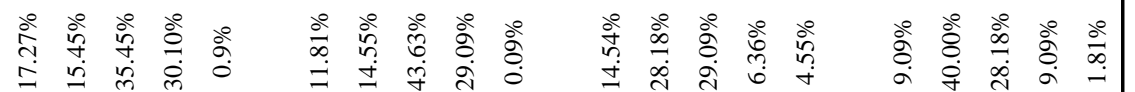
$\underline{I}$ 市 


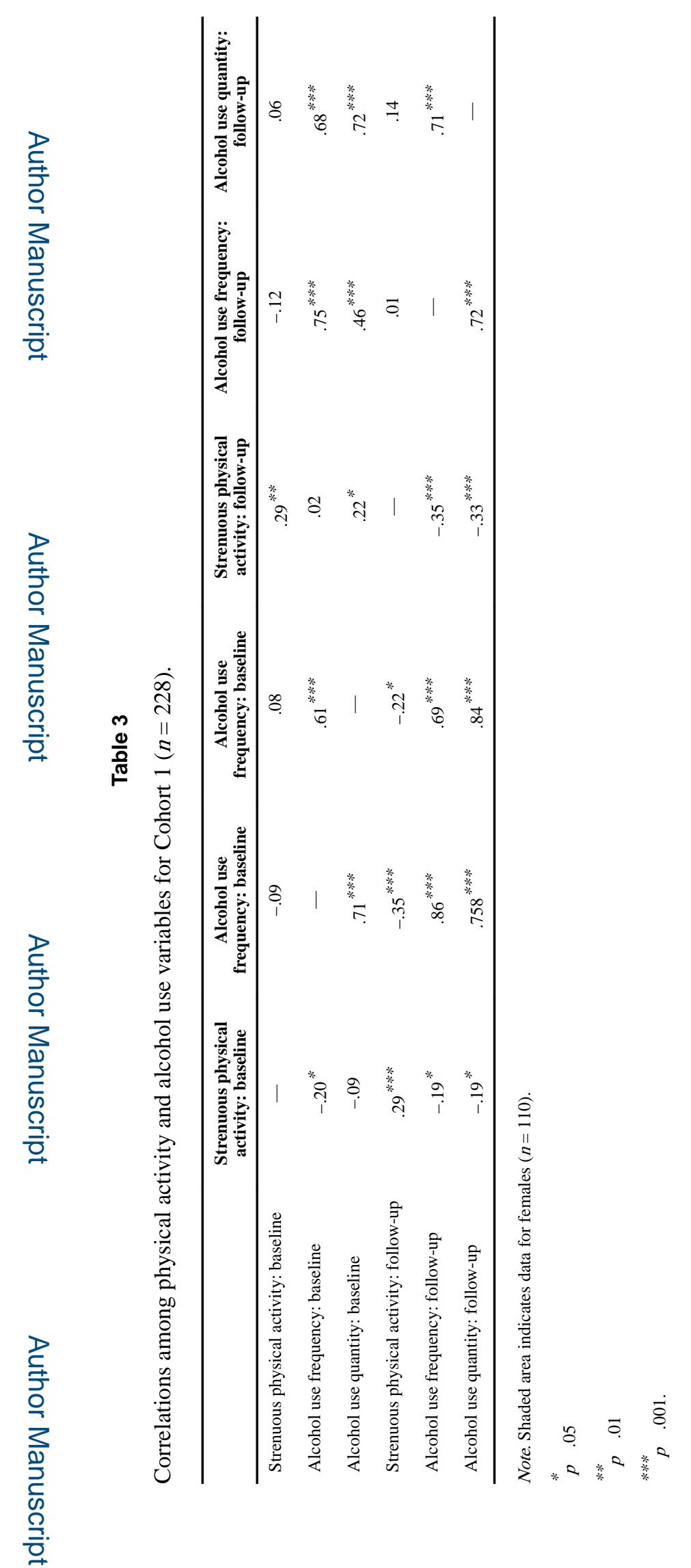

$J$ Am Coll Health. Author manuscript; available in PMC 2018 February 01. 


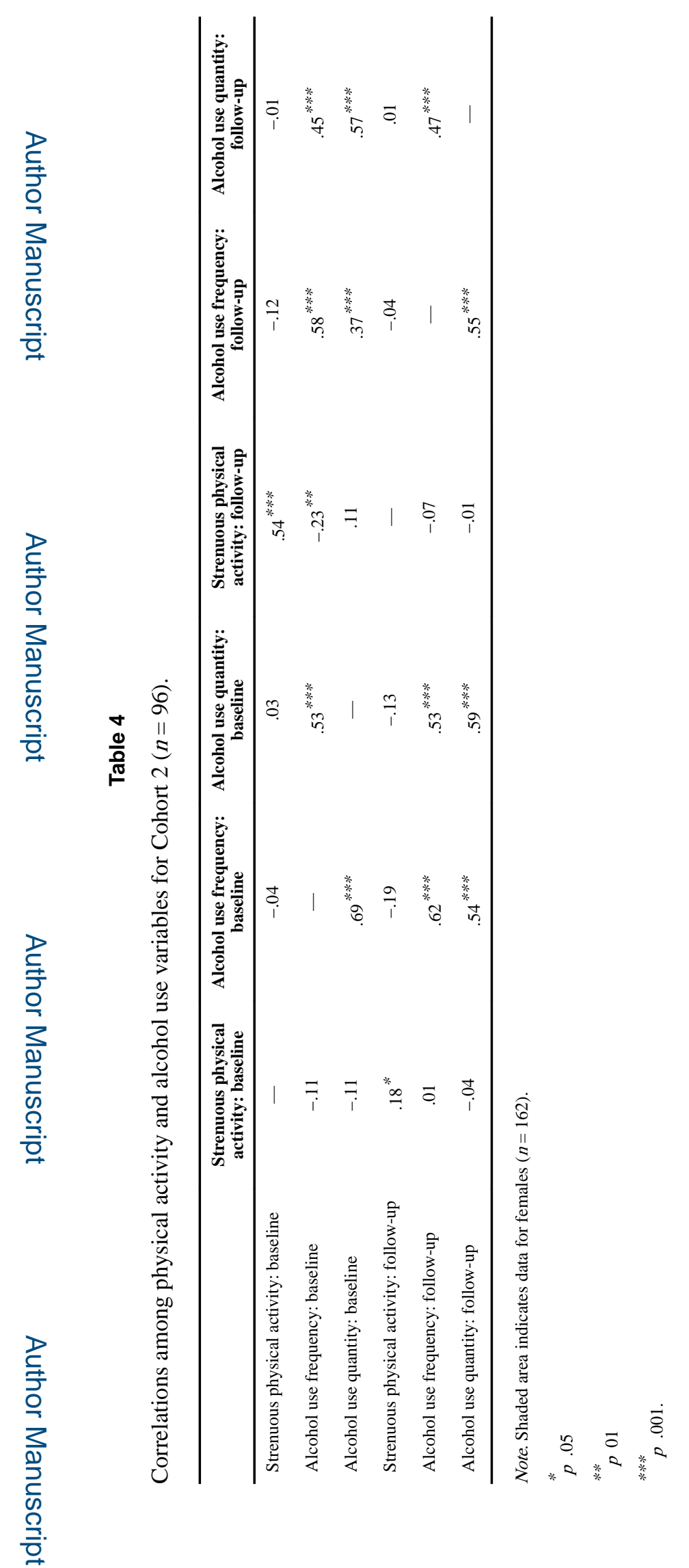

$J$ Am Coll Health. Author manuscript; available in PMC 2018 February 01. 